Vol. 1, No. 1 | January - June 2018

\title{
Solar Concentrator's Effect on Solar Panel Efficiency
}

\author{
Manoj Kumar Panjwani ${ }^{1,2}$, Li Meicheng ${ }^{2}$, Idris Khan ${ }^{2}$, Zulfiqar Ali $^{2}$, Mohan \\ Menghwar $^{2}$, Zulqarnain Arain ${ }^{1,2}$, Danish Khan ${ }^{2}$
}

\begin{abstract}
:
Given the current energy emergencies, the existing emphasis is increasing on the renewables as researchers predict near the end to fossils. In the light of the current renewable energy resources, the solar energy is seen to be one of the most reliable ones for the third world countries. Moreover, the efficiency of current commercial photovoltaics hardly touches $30 \%$. This paper studies the mechanism of empowering solar concentrators to collect higher solar irradiation to concentrate on the solar panel and study the variations in the amount of power received and the temperature constraints. The study utilises the use of solar concentrators in regions under and over the mentioned standard temperature ranges by the manufacturer on the specification sheet, and thoroughly studies the variations observed in output parameters.
\end{abstract}

Keywords: Solar Concentrator; Efficiency; Temperature; Renewable energy.

\section{Introduction}

The energy that is received directly from the sun is approximately near to $1413 \mathrm{~W} / \mathrm{m} 2$. However, the actual utilisation which is indicated on the ground scale is near to 1050 $\mathrm{W} / \mathrm{m} 2$ as reported by the United States Branch of Agriculture, Portland USA. In general, the

Earth's top layer is nearly 30\% more extreme than the one which is received on the ground. Most studies report that the real solar energy that is being utilised for the normal operation of the solar panel is nearly $70 \%$ of the total energy that is received directly from the sun on planet Earth. In other words, current photovoltaics utilises $70 \%$ of the energy received on the earth to satisfy our current energy demands [1-2].
The manufacturers of the Solar Panel are always required to display a specification list on the back of the Solar Panel. The specification list consists of the various parameters that the Solar Panel is going to respond. Most of the commercial Solar Panel manufacturers are reporting that their Panels would respond to the standard when exposed to irradiations of $1000 \mathrm{~W} / \mathrm{m} 2$ and $25 * \mathrm{C}$. In the case where the standard ranges are violated contribute to the irregular response from the Solar Panel, thus arising stability issues for the photovoltaic systems. More specifically, the Solar Panel is allowed to operate in areas which exceed the standard ranges of any parameter, which ultimately lead to increasing issues for the systems stability [3].

\footnotetext{
${ }^{1}$ Department of Energy Systems Engineering, Sukkur IBA University Pakistan

${ }^{2}$ Renewable Energy School, North China Electric Power University, Beijing China

Corresponding Email: manoj.panjwani@iba-suk.edu.pk 
If considering areas in most South Asian countries, the concern mostly raised by the manufacturer highlights the insights where there is an issue of increasing temperatures and most of the cities located in lower South Asian regions touches $50 * \mathrm{C}+$. Given the current situation, the temperature ranges offered by the regions allowed most of the Solar Panels to deviate from the standard performance[3-4].

It is very important to know the temperature of the solar panel before we could design the system to respond to certain energy demand from the community. It is also important to highlight that the behaviour of the Solar Panel concerning environmental parameters is irregular. Thus it allows the higher risk of instability issues for the systems which are off-grid and on-grid [5]. Considering the Polycrystalline Solar Panel, it indicates that when the temperature is decreased by one degree Celsius above $25^{*} \mathrm{C}$, the output power will also simultaneously affect. Moreover, it indicates a standard range where it maintains its temperature coefficient. However, it also indicates that the temperature coefficient values also appear differently when the temperature ranges enter into ranges higher than the critical range for the Solar Panel [6].

With an increasing demand of utilising the Solar concentrators in fulfilling the daily energy demands, the solar concentrators are also being utilised to allow a higher amount of Solar irradiations to concentrate on a particular area and could lead to the higher amount of power output from the existing Photovoltaic Plant. It's a matter of the fact that it's the solar irradiations that ultimately are converted into power output in photovoltaic's and not the heat. With empowering Solar concentrators on concentrating the number of irradiations can help the system to operate in a certain range, and once the standard temperature is crossed, it appears to display negative impact on the overall output of the Photovoltaic system. Moreover, utilising the Solar Panel in ranges above the standard ultimately lead to an unreliable response of the Panel on a longer run [7-8].

Pearson correlation coefficient is mostly utilised to understand the linear behaviour/connection between any two variables. It can also be used to carefully understand the behaviour of the system if there is any change in a specific variable(s) [9].

During experimental analysis, solar trackers were utilised to assure that the concentrator could respond to the peak hours to assure maximum power conversion for the system. The system comprised a controlled laboratory environment where it was directed to bring expansion of the temperature with increasing amount of irradiation from a light source. In corresponding, the behaviour of the solar panel was carefully studied and reported.

\section{Experimental Analysis}

Experimental setup included a controlled test bench which included a 50W BP Solar Panel (Polycrystalline) with specification Vamp(17.3V),Imp(2.9A),temperature coefficient of $\operatorname{Isc}(0.065 \pm 0.015) \% /{ }^{\circ} \mathrm{C}$, Temperature coefficient of $\operatorname{Voc}(-80 \pm 10)$ $\mathrm{mv} /{ }^{\circ} \mathrm{C}$ and Temperature coefficient of power $(-0.5 \pm 0.05) \% /{ }^{\circ} \mathrm{C}$. It also includes Hygrometer, Thermometer, six tungsten filament bulbs acting as load $(50,100,500,1000 \mathrm{~W})$, and 12 Millimeters for point to point calculations. The readings were carefully monitored with every increase in humidity and temperature ranges. Later the Solar Concentrator was employed to see the variations on the parameters affected. Results were carefully monitored, and Karachi,Pakistan (Latitude: 24.8934', Longitude: $67.0281^{\prime}$ ') was taken as a reference for experiments.

\subsection{Humidity's effect on Solar Panel}

The values of voltage, current, and power continue to depreciate as there is an increase in the amount of humidity as can be referred from Figure 1-3. Linear depreciation range could be seen from humidity range $25-30 \%$ as can be referred from Table 2 . With an increase 
in the temperature in the room, the range of humidity was found decreasing. There was a decreasing trend which was followed by the voltages and currents when a variation was brought in the temperature. Concerning Figure 4, few parameters were getting disturbed when it comes to utilising the Solar Panels. A significant decrease in the voltage and humidity were noticed as there was a linear increase in the temperature ranges. Figure 4 reflects the effect of temperature increase on the produced current. The current follows an unusual behaviour when there is a variation on the temperature.

With an increasing level of humidity ranges, there is a decrement noticed on the number of voltages produced which also appears to cause various issues on the system's stability and overall performance as can be referred from Equation 1 [10].

The similar trend could be referred to the amount of current produced with the variation brought in the amount of humidity. Thus the similar trend would also lead to increased stability issues for the system. The interesting fact noticed in the experiment shows that there is no constant trend followed by the current when there is variation brought on the system.

With the current trend followed on the amount of power produced by the solar panel concerning variations brought from the variations in the humidity, various instability issues are ultimately leading to the unreliability of the photovoltaic systems as can be referred from Table 1 .

\subsection{Usage of Solar Concentrator}

Solar concentrators are employed for various reasons including one for heating water and thermal energy production. Moreover, they are currently employed to study their contribution to the increasing energy productions for the Solar Panel. Solar Concentrators could help in collecting higher intensities for the efficient energy conversion. The concentrators that were utilized in the experiment setup had a dimension of $850 \mathrm{x}$ $565 \times 50 \mathrm{~mm}$ which was utilized to cover the area of a $50 \mathrm{~W}$ solar panel. The side angle was kept 30 degrees for a reasonable tilt to encourage maximum power conversion.

It can be easily noticed that with the increasing pattern of solar intensity over Solar Panel, there is a consequent increase in the amount of surface temperature on the Solar Panel. With increasing temperature, various issues can be associated with the temperature coefficient mentioned in the manufacturer's specification list. Ultimately, it starts deviating from the standard range, and hence there are stability issues that arise. Moreover, the increasing temperature though somehow contribute positively as the amount of humidity that appears on the surface of solar panel starts decreasing making Solar Panel easy to convert the irradiations into electrical energy as can be referred from Table 2 .

Concerning the decreasing humidity because of the increasing temperature on the panel, despite the fact that humidity negatively affects the performance of Solar Panel, there is a decrease noticed in the current produced by the system. In result of a decrease in the amount of current from the system, various issues lead to unstable behaviour of the system as can be referred from Table 3 .

Due to continuous increment in the temperature ranges due to increase in the solar intensity, there is an irregular pattern followed by the power output. There are various reasons due to which it follows irregular behaviour, and most of them reflect the internal material characteristics of the material used in the manufacturing of the Solar Panel. The respective reading of irregular behaviour could be referred from Table 4 and 5 and can be related from Equation 2 and 3 [10].

From Table 6, the Pearson correlation value as stated in Equation 4 is used for a default value under the range of parameters listed by the manufacturer. It can be seen that in the range of $\left(6.85^{*} \mathrm{C}-36.85^{*} \mathrm{C}\right)$, correlation of the photovoltaic power and solar radiation is greater than 0.85 which indirectly states that the solar radiation is the main factor that affects the output power from 
the Solar Panel. Moreover, the temperature has a positive effect which means that the temperature increase in the region under the region specified can positively affect the power output of the panel. The results can also be verified referring the value of the power and the temperature in table 4 . However, the humidity range can be seen portraying a negative value which states that the humidity negative impacts the overall power output from the Solar Panel. Moreover, the value of the wind also has a little positive impact in a sense that the wind would provide the ventilation effect to the solar panel which varies from region to region.

From Table 7, The Pearson correlation value is used for a default value over the range of parameters listed by the manufacturer. It can be seen that in the range of $(36.85 * \mathrm{C}$ $58.70 * \mathrm{C}$ ), correlation of the photovoltaic power and solar radiation is greater than 0.85 which also validates the importance of the solar radiation in the overall power output of the Panel. However, the interesting aspect of it lies in the temperature where the coefficient shows a negative value. The negative value shows that the temperature in a range higher than those indicated by the manufacturer has a negative impact on the power produced by the Solar Panel. The aspect could be seen validating the results obtained in Table 5. The same aspect can be seen from the humidity's part also that it also portrays a negative impact on the power produced by Solar Panel. However, wind factor could be seen positive so that the Solar Panel is exposed to need of ventilation for the said aspect.

The results indicated after various attempts on the Solar Panel with variations from in the solar intensities from temperature range $6.85 * \mathrm{C}-36.85 * \mathrm{C}$ shows a positive change in the output power output. However, once the temperature of $36.85^{*} \mathrm{C}$ is crossed, it starts portraying negative effect on the power output from the photovoltaic system. With an increasing trend from $36.85^{*} \mathrm{C}-56.70^{*} \mathrm{C}$, the power output could be seen decreasing and arising many concerns over the stability of the installed photovoltaic system.

\section{Tables, Figures, and Equations}

\subsection{Tables}

TABLE 1. Experimental Values of Voltage (V), Current (A) and Power (W) with increasing trend in Humidity (\%) on constant Solar Irradiance [9].

\begin{tabular}{|c|l|l|r|l|c|}
\hline $\begin{array}{c}\text { Solar } \\
\text { Irradiance } \\
(\mathrm{W} / \mathrm{m} 2)\end{array}$ & $\begin{array}{r}\text { Temperat } \\
\text { ure }\end{array}$ & $\begin{array}{r}\text { Humidity } \\
(\mathrm{C})\end{array}$ & $\begin{array}{r}\text { Voltage } \\
(\mathrm{V})\end{array}$ & \multicolumn{1}{|c|}{$\begin{array}{c}\text { Current } \\
\text { (Amp) }\end{array}$} & $\begin{array}{c}\text { Powers } \\
\text { (watts) }\end{array}$ \\
\hline 800 & 31.85 & 40 & 17.1 & 2.41 & 41.21 \\
\hline 800 & 31.85 & 45 & 16.89 & 2.34 & 39.52 \\
\hline 800 & 31.85 & 50 & 16.75 & 2.21 & 37.08 \\
\hline 800 & 31.85 & 55 & 16.54 & 2.14 & 35.39 \\
\hline 800 & 31.85 & 60 & 16.45 & 2.02 & 33.22 \\
\hline 800 & 31.85 & 65 & 16.35 & 1.92 & 31.39 \\
\hline 800 & 31.85 & 70 & 16.32 & 1.84 & 30.02 \\
\hline
\end{tabular}


TABLE 2. Solar irradiance calculated with and without concentrator with percent increase.

\begin{tabular}{|c|l|c|}
\hline $\begin{array}{c}\text { Solar Irradiance } \\
(\mathrm{W} / \mathbf{m 2}) \text { Without } \\
\text { Concentrator }\end{array}$ & $\begin{array}{l}\text { Solar Irradiance } \\
(\mathrm{W} / \mathbf{m 2}) \text { with } \\
\text { Concentrator }\end{array}$ & Percent Increase \\
\hline 650 & 693 & 6.20 \\
\hline 730 & 786 & 7.12 \\
\hline 820 & 869 & 5.63 \\
\hline 915 & 962 & 4.88 \\
\hline 985 & 1037 & 5.01 \\
\hline 1028 & 1086 & 5.34 \\
\hline 1134 & 1197 & 5.26 \\
\hline
\end{tabular}

TABLE 3. Power output calculated with Solar Concentrator.

\begin{tabular}{|c|c|c|c|c|c|}
\hline $\begin{array}{c}\text { Solar Irradiance } \\
(\mathrm{W} / \mathbf{~ m 2})\end{array}$ & $\begin{array}{c}\text { Humidity } \\
(\%)\end{array}$ & $\begin{array}{c}\text { Temperature } \\
\text { at the Panel } \\
(\mathrm{C})\end{array}$ & $\begin{array}{c}\text { Voltage } \\
(\mathrm{V})\end{array}$ & $\begin{array}{c}\text { Current } \\
\text { (Amp) }\end{array}$ & $\begin{array}{c}\text { Powers } \\
\text { (watts) }\end{array}$ \\
\hline 650 & 25 & 31.85 & 16.3 & 2.12 & 34.56 \\
\hline 730 & 25 & 32.35 & 16.9 & 2.24 & 37.86 \\
\hline 820 & 25 & 32.85 & 17.1 & 2.31 & 39.50 \\
\hline 915 & 24 & 33.15 & 17.11 & 2.37 & 40.55 \\
\hline 985 & 23 & 33.85 & 17.14 & 2.42 & 41.48 \\
\hline 1028 & 22 & 34.55 & 17.15 & 2.49 & 42.70 \\
\hline 1134 & 21 & 35.33 & 17.15 & 2.51 & 43.04 \\
\hline
\end{tabular}

TABLE 4. Calculated parameters with Solar Concentrator in the temperature range $\left(6.85^{*} \mathrm{C}-36.85^{*} \mathrm{C}\right)$.

\begin{tabular}{|c|c|r|r|r|r|r|}
\hline $\begin{array}{c}\text { Solar } \\
\text { Irradiance } \\
(\mathrm{W} / \mathrm{m} 2)\end{array}$ & $\begin{array}{c}\text { Concentrated } \\
\text { Irradiations(W/ } \\
\mathrm{m} 2)\end{array}$ & $\begin{array}{c}\text { Temperature } \\
\text { at } \\
\text { the } \\
\text { Panel } \\
(\mathrm{C})\end{array}$ & $\begin{array}{l}\text { Humidity } \\
(\%)\end{array}$ & $\begin{array}{l}\text { Voltage } \\
(\mathrm{V})\end{array}$ & $\begin{array}{l}\text { Current } \\
\text { (Amp) }\end{array}$ & $\begin{array}{l}\text { Powers } \\
\text { (watts) }\end{array}$ \\
\hline 650 & 693 & 6.85 & 25 & 16.5 & 2.14 & 35.31 \\
\hline 730 & 786 & 11.85 & 25 & 16.9 & 2.24 & 37.85 \\
\hline 820 & 869 & 16.85 & 25 & 17.1 & 2.31 & 39.50 \\
\hline 915 & 962 & 21.85 & 24 & 17.15 & 2.42 & 41.50 \\
\hline 985 & 1037 & 26.85 & 23 & 17.16 & 2.48 & 42.55 \\
\hline 1028 & 1086 & 31.85 & 22 & 17.16 & 2.52 & 43.24 \\
\hline 1134 & 1197 & 36.85 & 21 & 17.18 & 2.61 & 44.83 \\
\hline
\end{tabular}


Manoj Kumar Panjwani (et al.), Solar Concentrator's Effect on Solar Panel Efficiency

(pp. 15 - 27)

TABLE 5. Calculated parameters with Solar Concentrator in the temperature range $(26.85 * \mathrm{C}-58.70 * \mathrm{C})$.

\begin{tabular}{|c|c|r|r|r|r|r|}
\hline $\begin{array}{c}\text { Solar Irradiance } \\
(\mathrm{W} / \mathbf{m} 2)\end{array}$ & Concentrated & $\begin{array}{r}\text { Temperature } \\
\text { Itradiations(W/m2) }\end{array}$ & $\begin{array}{r}\text { Humidity } \\
(\%) \\
(\mathrm{C})\end{array}$ & $\begin{array}{r}\text { Voltage } \\
(\mathrm{V})\end{array}$ & $\begin{array}{r}\text { Current } \\
(\text { Amp })\end{array}$ & $\begin{array}{c}\text { Powers } \\
(\text { watts })\end{array}$ \\
\hline 650 & 693 & 26.85 & 25 & 16.85 & 2.04 & 34.37 \\
\hline 730 & 786 & 31.85 & 25 & 16.9 & 2.08 & 35.15 \\
\hline 820 & 869 & 36.85 & 25 & 16.7 & 2.12 & 35.40 \\
\hline 915 & 962 & 41.85 & 23 & 16.32 & 2.13 & 34.76 \\
\hline 985 & 1037 & 46.85 & 21 & 15.37 & 2.14 & 32.89 \\
\hline 1028 & 1086 & 51.85 & 19 & 14.8 & 2.16 & 31.97 \\
\hline 1134 & 1197 & 58.70 & 16 & 14.25 & 2.19 & 31.21 \\
\hline
\end{tabular}

TABLE 6. Pearson correlation coefficient for PV power with meteorological factors in the temperature range $\left(6.85 * \mathrm{C}-36.85^{*} \mathrm{C}\right)$.

\begin{tabular}{lllll}
\hline $\begin{array}{l}\text { Weather } \\
\text { Type }\end{array}$ & Radiation & Temperature & Humidity & $\begin{array}{l}\text { Wind } \\
\text { speed }\end{array}$ \\
\hline Sunny & 0.915436 & 0.389721 & -0.35921 & 0.22321 \\
\hline Foggy & 0.909706 & 0.365947 & -0.34865 & 0.21479 \\
\hline Rainy & 0.889801 & 0.301972 & -0.32875 & 0.16826 \\
\hline
\end{tabular}

TABLE 7. Pearson correlation coefficient for PV power with meteorological factors in the temperature range $(36.85 * \mathrm{C}-58.70 * \mathrm{C})$.

\begin{tabular}{lllll}
\hline $\begin{array}{l}\text { Weather } \\
\text { Type }\end{array}$ & Radiation & Temperature & Humidity & $\begin{array}{l}\text { Wind } \\
\text { speed }\end{array}$ \\
\hline Sunny & 0.92443 & -0.31891 & -0.24334 & 0.21551 \\
\hline Foggy & 0.91704 & -0.278663 & -0.32654 & 0.20267 \\
\hline Rainy & 0.89501 & -0.299886 & -0.27752 & 0.14722 \\
\hline
\end{tabular}




\subsection{Figures}

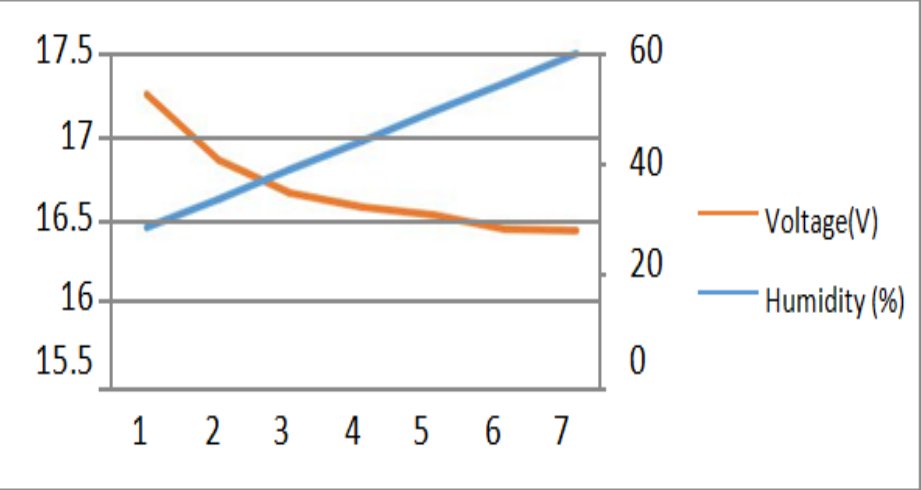

Fig. 1. Figure portrays the effect of Humidity on Voltage Produced.

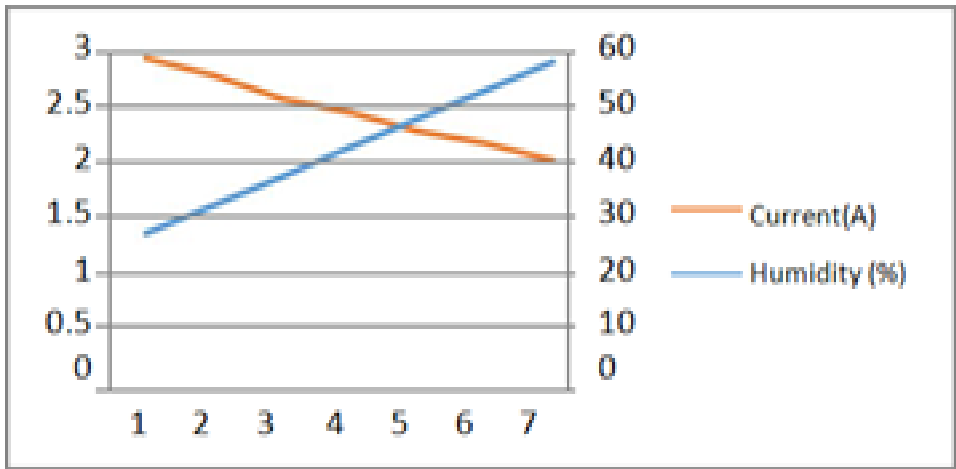

Fig. 2. Figure portrays the effect of humidity on the Current produced.

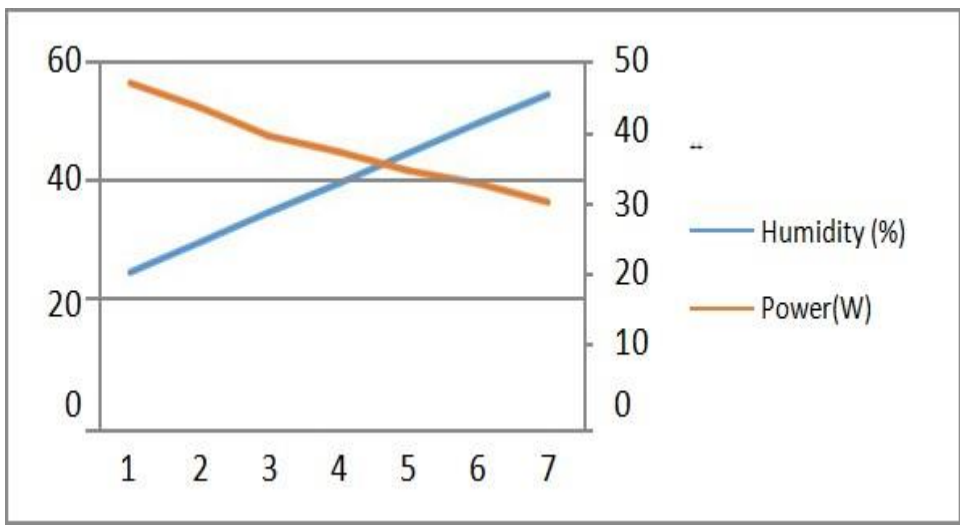

Fig. 3. Figure portrays the effect of Humidity on Power Produced. 


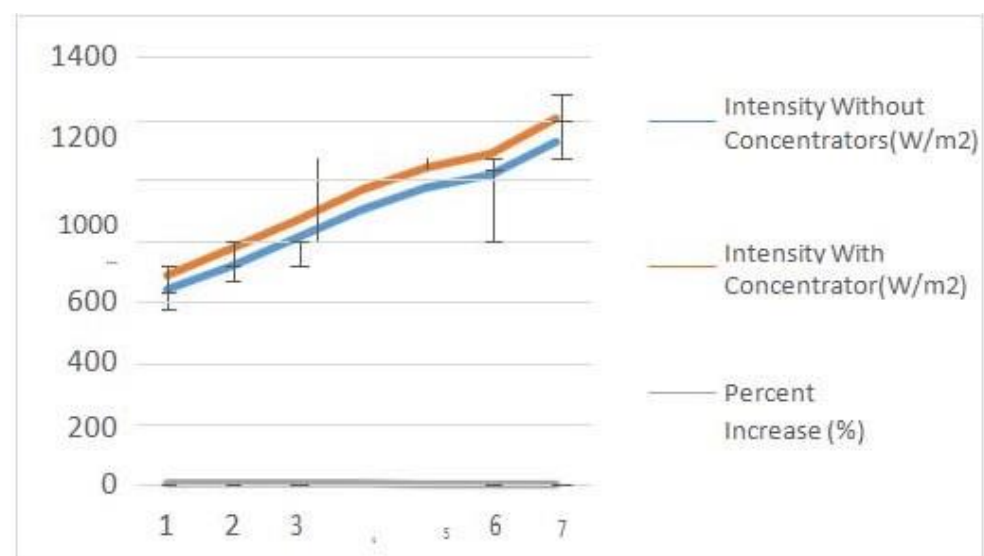

Fig. 4. Graph is portraying an increase in the solar intensity collected at the surface of the Solar Panel due to Solar Concentrator.

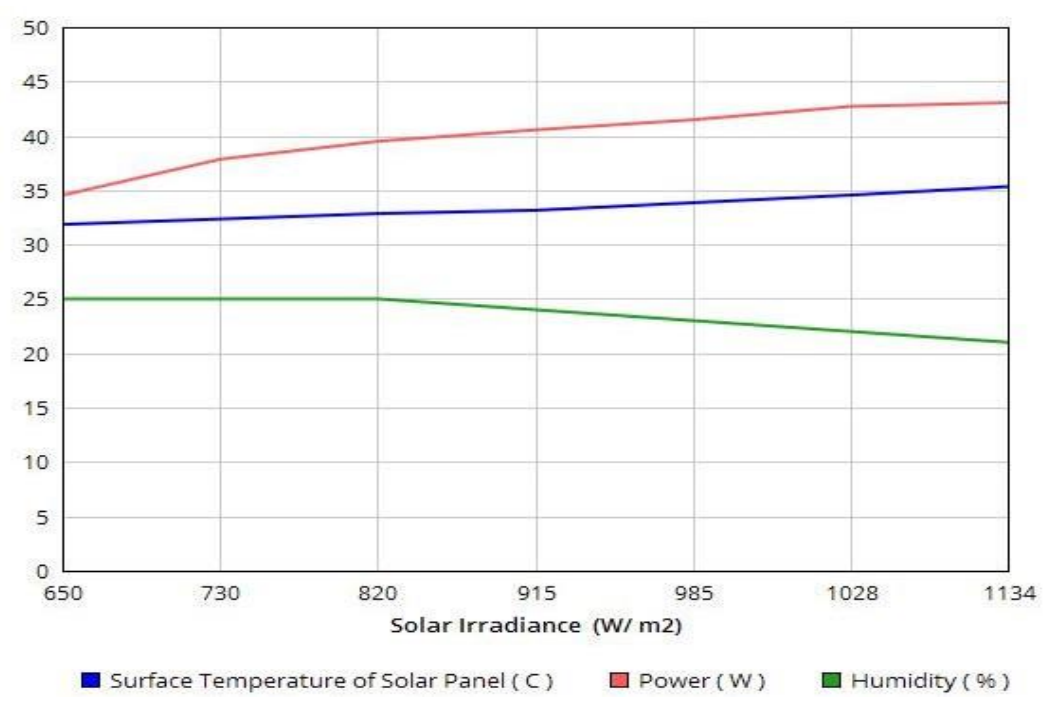

Fig. 5. The graph is portraying the effect of increase in the solar irradiations on Panel's Power Output, Humidity and Surface Temperature. 


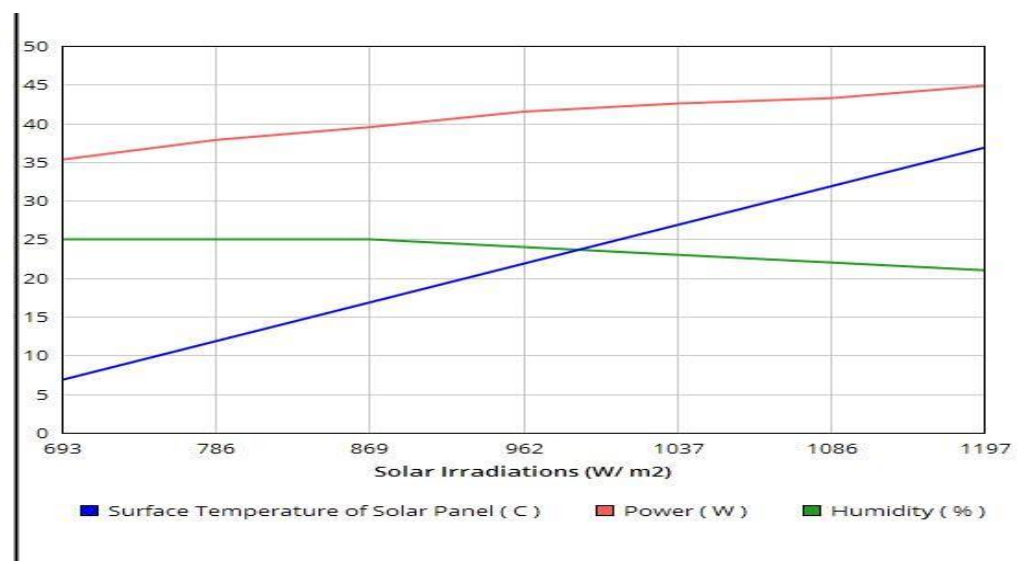

Fig. 6. Graph portraying the effect of an increase in the solar irradiations on Panel's Power Output, Humidity and Surface Temperature in Temperature ranges $(6.85 * \mathrm{C}-36.85 * \mathrm{C})$.

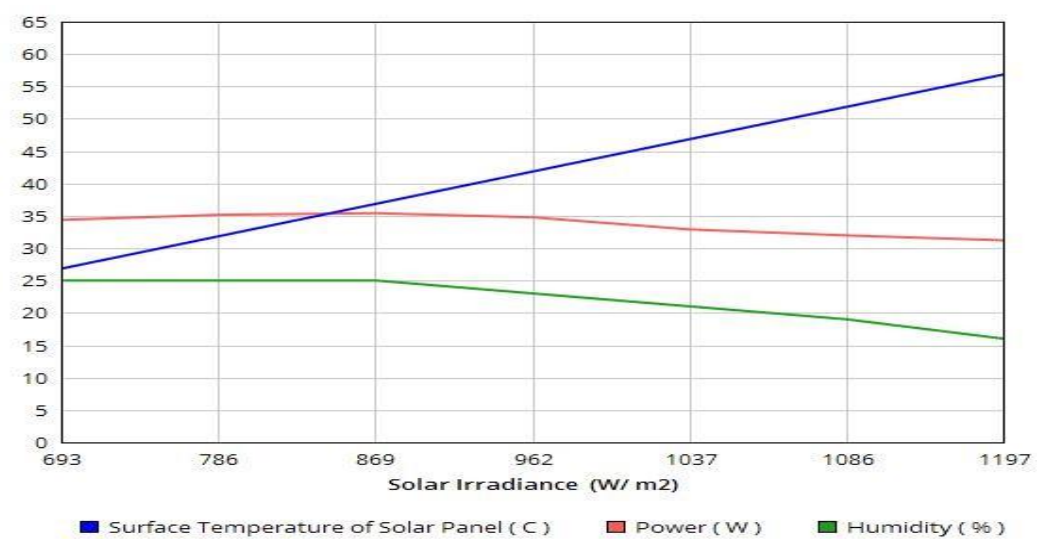

Fig. 7. Graph portraying the effect of an increase in the solar irradiations on Panel's Power Output, Humidity and Surface Temperature in Temperature ranges $\left(26.85^{*} \mathrm{C}-58.70 * \mathrm{C}\right)$.

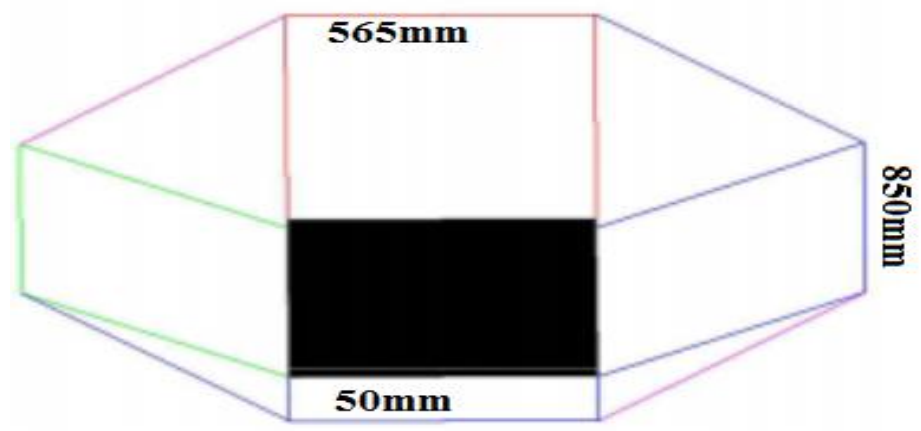

Fig. 8. Shows the solar concentrator used for the experimental analysis ( 850 x 565 x 50mm).

Sukkur IBA Journal of Emerging Technologies - SJET | Volume 1 No. 1 January - June 2018 (C) Sukkur IBA University 


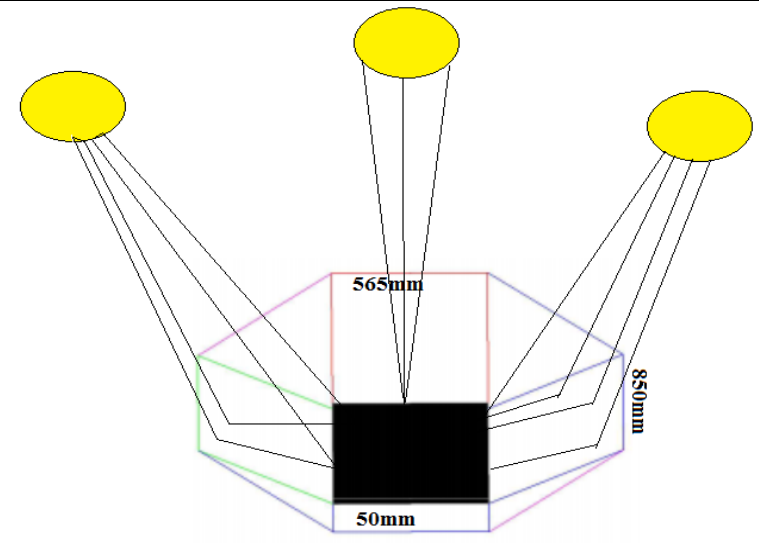

Fig. 9. Design of the static solar concentrator mechanism utilizing the peak hours.

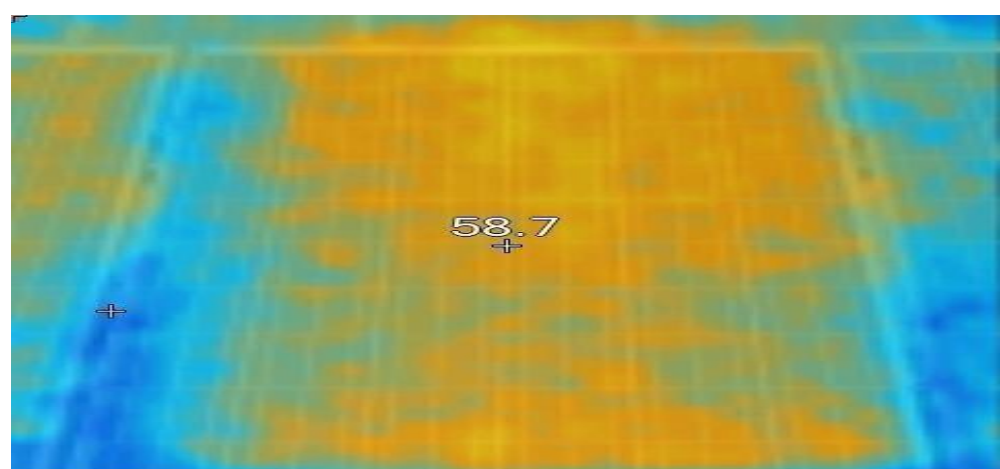

Fig. 10. Portrays areas which are under high temperature because of the solar concentrator at $58.7 * \mathrm{C}$.

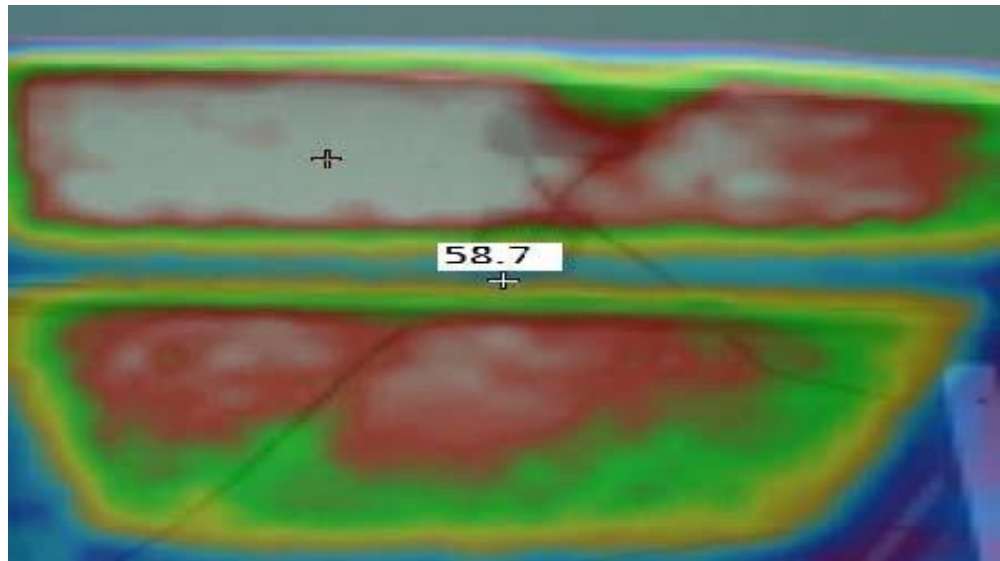

Fig. 11. Portrays areas at the backside of the Solar Panel at $58.7^{*} \mathrm{C}$. 


\subsection{Equations}

Voc module $=$ Temp coefficient $*($ Tstc $-\mathrm{T}$ ambient $)+$ Voc rated

Where:

Voc, $\bmod =$ open circuit voltage at module temperature

Tstc $\left[{ }^{\circ} \mathrm{C}\right]=$ temperature at standard test conditions, $25{ }^{\circ} \mathrm{C}, 1000 \mathrm{~W} / \mathrm{m} 2$ solar irradiance

Tambient $\left[{ }^{\circ} \mathrm{C}\right]=$ Module temperature Voc,rated $=$ open circuit voltage at STC .

$$
\begin{aligned}
P_{i} & =\int_{0}^{\infty} E(\lambda) d \lambda \\
J_{s c} & =\int E(\lambda) \operatorname{SR}(\lambda) d \lambda \\
\rho_{A, B} & =\frac{\operatorname{cov}(A, B)}{\sqrt{\operatorname{cov}(A, a)} \sqrt{\operatorname{cov}(B, b)}}
\end{aligned}
$$

\section{Results and Discussions}

As per the results validated and investigated, it's well understood that the photovoltaic systems appear to be working efficiently if there is solar concentrator's used within the specified region mentioned by the manufacturer on the specification list. The solar concentrator is successful in collecting a significant amount of radiation to be converted.

It can be referred from Figure 4 and Figure 5 , that with an increase in the irradiations, there is a considerable increase in the temperature noticed and there is an irregular behaviour of the system noticed when the temperature ranges are brought to variant as specified on the specification list.

It can be referred from Figure 6 that when operating the Solar Panel from the range $6.85^{*} \mathrm{C}-36.85^{*} \mathrm{C}$, the system is seen to deliver a higher amount of Power Output. However, referring to Figure 7, when the specified range is surpassed, there appears decrement in the Power Output which indirectly makes the system more unstable and unreliable.
The Solar Concentrator's specification is specified in Figure 8 which are incorporated in the experimental setup. From Figure 9, it can be deduced that the solar concentrators can be incorporated to cover a specified angle to cover and utilize the peak hours for the photovoltaic system.

Referring Figure 10, it can be observed that when the Solar Panel is exposed to Solar Concentrator, the centre of the Solar Panel is studied to have been exposed to increasing temperature which indirectly leads to irregular behaviour of the Solar Panel when the specified temperature range is surpassed. Moreover, in the view of Figure 10, the sides of the Solar Panel could be seen experiencing lesser temperature effect as compared to the centre part because of utilising the Solar Concentrators.

Moreover, referring Figure 11, the impact of the Solar Concentrator could be seen at the back of the Panel which is also experiencing a shift in the temperature ranges and is indicated by reddish colour.

Considering the facts mentioned above and figures utilising Solar Concentrator in ranges 
below mentioned could help in enhancing the power efficiency by utilising the Solar Concentrators. Various experiments were conducted to validate the idea of increasing and decreasing of Power Output concerning solar radiations concentrated and allowed to hit the Solar Panel.

\section{Conclusion}

The thorough investigation was carried out to properly study and validate the idea of incorporating the Solar Concentrator on the Solar Panel to enhance the Power Efficiency. There is significant need to allow few changes to the Photovoltaic System to allow a stable and reliable response. The proposed idea was seen working effectively in ranges identified as $6.85^{*} \mathrm{C}-36.85^{*} \mathrm{C}$ where in response to increasing solar intensity, the power output was seen increasing. However, the studied range from $36.85^{*} \mathrm{C}-58.70^{*} \mathrm{C}$ was seen negatively contributing to the Power Output and hence it was seen decreasing with increasing of Solar Intensity and Surface Temperature of the Solar Panel. Therefore, predefined measures are to be considered before utilising the Solar Concentrators in areas that are hot and humid.

\section{Future Recommendations}

Given the irregular response of the Solar Panel with incorporating Solar Concentrator, heat sinks could help to control the overall temperature ranges of the Solar Panel. Moreover, there could be additional ventilation factor that could be studied before incorporating the Solar Concentrators in areas under and above the standard range as specified by the specification list. Additional ventilation could help effectively in increasing the overall stability and long-run durability of the Photovoltaic System. Additionally, there is a prompt need for self-cleaning of the Solar Panel that could also positively help in utilizing the proper conversion of the irradiation as there is a mixture of water and dust that forms a layer on the Solar Panel. However, there could be different Solar Panels that could be manufactured to be exposed to areas which are hot and humid.

\section{ACKNOWLEDGMENT}

I would like to extend my thanking remarks to Professor Qi Zheng from North China Electric Power University for the support and technical guidance. Moreover, An earlier version of this paper was presented at the International Conference on Computing, Mathematics and Engineering Technologies (iCoMET 2018) and was published in its Proceedings available at IEEE Explorer. DOI: 10.1109/ICOMET.2018.8346439.

\section{REFERENCES}

[1] M. Chegaar and P. Mialhe, "Effect of atmospheric parameters on the silicon solar cells performance" Journal of Electron Devices, vol. 6, pp. 173-176, 2008.

[2] R. Gottschalk, D. G. Infield, and M. J. Kearney, "Influence of environmental conditions on the outdoor performance of thin film devices," In 17th European Photovoltaic Solar Energy Conference, 2001.

[3] Raghunathan, Vijay, A. Kansal, J. Hsu, J. Friedman, and M. Srivastava, "Design considerations for solar energy harvesting wireless embedded systems," In Proceedings of the 4th international symposium on Information processing in sensor networks, pp. 64. IEEE Press, 2005.

[4] Zeller, Peter, and H. M. Libati, "Utilization of solar energy for electrical power supply in rural African areas," In AFRICON 2009 (AFRICON'09, ) pp. 1-6. IEEE.

[5] Ahmed, M. Mohamud and M. Sulaiman, "Design and proper sizing of solar energy schemes for electricity production in Malaysia," In Power Engineering Conference, 2003. PECon 2003, 
Proceedings. National, pp. 268-271.

IEEE, 2003.

[6] Omubo-Pepple, V. B., C. Israel-Cookey, and G. I. Alaminokuma, "Effects of temperature, solar flux and relative humidity on the efficient conversion of solar energy to electricity," European Journal of Scientific Research, vol. 35, no. 2, pp. 173-180, 2009.

[7] G. Mostafa and F. Khan, "An efficient method of the solar panel energy measurement system," 1st International Conference on the Developments in Renewable Energy Technology (ICDRET), 2009, pp. 1-3, IEEE.

[8] M. C. Alonso-Garcia, J. M. Ruiz, and F. Chenlo, "Experimental study of mismatch and shading effects in the I-V characteristic of a photovoltaic module," Solar Energy Materials and Solar Cells vol. 90, no. 3, pp. 329-340, 2006.

[9] Karl Pearson (20 June 1895), Notes on regression and inheritance in the case of two parents. Proceedings of the Royal Society of London, vol. 58, pp. 240-242.

[10] M. K. Panjwani, S. K. Panjwani, F. H. Mangi, D. Khan, and L. Meicheng, "Humid free efficient solar panel," In AIP Conference Proceedings, vol. 1884, no. 1, p. 020002. AIP Publishing, 2017. 